\section{Book Review: Hannah}

\section{Frank, Frame by Frame:}

A Materialist Aesthetics

of Animated Cartoons

(University of California

Press, 2019)
ब나

Open Library of Humanities

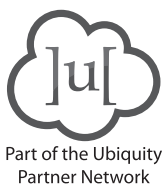

CORRESPONDING AUTHOR:

Malcolm Cook

University of Southampton, GB

m.cook@soton.ac.uk

KEYWORDS:

Animation; cartoons;

materialism; aesthetics

TO CITE THIS ARTICLE: Cook, M. 2021. Book Review: Hannah Frank, Frame by Frame: A Materialist Aesthetics of Animated Cartoons (University of California Press, 2019). Open Screens, 4(1): 12, pp. 1-4. DOI: https://doi. org/10.16995/os.64 


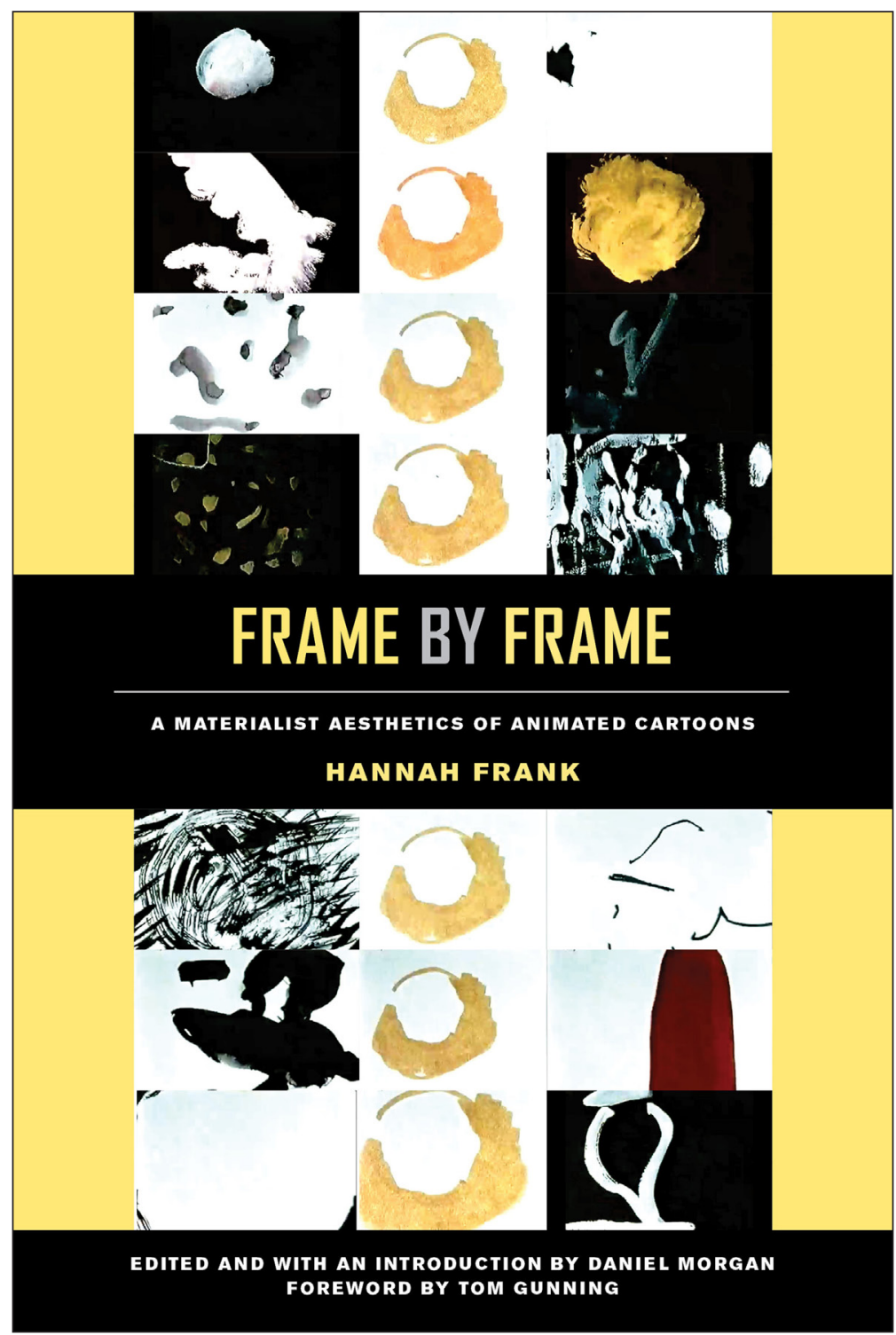

Life and movement are central principles of animation studies, rooted in the etymology of the word 'animation'. But what happens to animated cartoons when we still that movement or halt that life?

This is the question posed by Hannah Frank's Frame by Frame: A Materialist Aesthetics of Animated Cartoons. Frank's primary method is to examine animated cartoons cel by cel, to discover their hidden details and explore the implications she finds there. As she puts it 'I thus inaugurate a study of the single frame, the single document, in which the tiniest of details - a brushstroke, a shadow, an errant speck of dust-is freighted with historical and, ultimately, political weight' (15). Frank readily admits that to examine thousands of cartoons, each made up of thousands of individual drawings is 'an impossible task, a foolhardy task' (15). Yet in so doing, she not only rethinks our understanding of animation, but also transforms the way film theory should understand the photographic basis of cinema, as she detaches cinema's indexical trace of the world from its iconic resemblance.
Frank's corpus is studio-era American animated cartoons, those seven-minute wonders produced by Disney, Leon Schlesinger/Warner Bros., Fleischer, Walter Lantz, and MGM and featuring characters like Mickey Mouse, Bugs Bunny, Popeye, Woody Woodpecker, and Tom and Jerry. This is the most attended to and celebrated period of animation history, yet Frank shows that there is a great deal more still to be said about it. Her closest of close textual analysis uncovers some remarkable discoveries within these films: an original drawing of Woody Woodpecker masquerading as a blank frame, a momentarily headless Bugs Bunny resulting from a lapse of attention by a camera operator, single frame abstract expressionist paintings made by uncredited female labourers. Frank places these alongside experimental animation, especially that of Robert Breer, making a persuasive case for reconsidering distinctions between commercial and avant-garde animation.

The hidden labour of animation is of central concern here. Frank recognises the 'power of movement to occlude the labour behind it' (9). When cartoon 
characters move we cannot help but see them as alive and their movement is seemingly driven by their own agency. Frank's attention to the motionless frame is thus a political act since it enables an excavation of the human labour behind the moving image. 'By arresting the animation of animation, I aim to return cartoons to how they were made: one drawing at a time, one photograph at a time, one frame at a time' (2) and in so doing she can 'revivify the divided labor process' (6). Hidden details, mistakes and the materiality of animated films, uncovered by Frank's meticulous attention, are revealing of the people and processes that created them.

The place of photography in the production process of cel animated cartoons provides both practical and theoretical significance to this study. Drawn animation has long been assumed to be the antithesis of the photographic basis of cinema, and one reason for the prior exclusion of animation from the cinematic canon and film theory. Frank upturns this by noting that photography was a fundamental part of the production of these animated cartoons and that as such 'animated cartoons can be understood as photographic records of their own production' (11). In common with so many great works of criticism, Frank's brilliance here is to offer never before articulated meanings in a way that makes them self-evident and irrefutable. Moreover, this not only brings new insight to animation studies, but refigures entrenched ideas of film theory, such as Frank's insightful engagement with Bazin. Many film theorists will issue cartoon-sized gulps on reading this book.

Frame by Frame is divided into four chapters, bookended by an introduction and conclusion. Each main chapter addresses its theoretical and aesthetic concerns in relation to a specific part of the cel animation production process and the personnel responsible: animation, camera, painting, and inking/xerography. Chapter one highlights the intentional but hidden labour of the animation process. The familiar cartoon trope of presenting a newspaper headline provides a telling example here in two ways. Like Frank's own method, a newspaper page presented full-screen halts the movement of a cartoon, saving the labour of redrawing each frame for a few seconds. Moreover, Frank's close examination reveals the material conditions of the cartoon's production, whether it is the social and political contexts of the real newspapers altered for the narrative, or the efficient reuse of the same front page in multiple cartoons. In parallel, chapter one provides a compelling interdisciplinary theorisation of her method ranging from Walter Benjamin and Sergei Eisenstein to Emily Dickenson, microfilm archives and the scans created for Google Books.

Chapter two turns towards the unintentional within animated cartoons: the incidental, accidental and chance traces captured or created by the process of individually photographing thousands of cels and backgrounds. In the absence of other forms of primary documentation, the cartoon film records a particular form of evidence: 'To see animation as photography is... to see the labor that went into the film's making. Each and every animated cartoon is a photographic archive, and each and every one of its constitutive frames doubles as a visual catalogue of imperfections, anomalies, and disturbances' (67). Nevertheless here, as throughout the book, Frank acknowledges a haunting uncertainty about the examples given. Are they intentional, if hidden, acts of artistry, inadvertent results of the labour of production, or markers of the materiality of the media? Frank makes productive use of this uncertainty, arguing they 'do not occlude the object but instead reveal the nexus of social, technological, and economic practices that is the photographic apparatus' (73).

Chapter three continues the question of intentionality by posing the idea of the 'deliberate mistake' (80). This seemingly paradoxical concept allows a space to explore the uncertainty of intentionality, the unknowability of determining whether something in a film is purposeful or contingent. Frank considers these questions in relation to the work of the ink and paint department, whose exclusively female ranks played a crucial role in the animation process but were denied credit for the artistry they provided. Frank's forensic approach serves to reinstate this female labour into our understanding of these cartoons. Frank is less concerned with unearthing named individuals than with recognising their collective production and the way individual parts contribute to the whole, both at the aesthetic level of the film and within the organisation of the labour of the animation studio.

Chapter four brings together the strands from earlier chapters in a detailed reading of the introduction of xerography during the production of Disney's One Hundred and One Dalmatians. Frank recognises the complexity of this technology and the discourse surrounding it. The question of whether xerography preserves the original or reproduces and transforms it in turn prompts a reflection on the nature of the drawn line as image or text. Disney's film provides the perfect case study for this, as not only did its production depend on this new technology and its implications, but the film's narrative is about the similarities and differences entailed in reproduction.

Chapter four and the book as a whole undoubtedly have a lingering elegiac undertone to them. Its gaze is concentrated on a departed period and obsolete animation technologies and production processes. Frank makes clear that this study is predicated upon digital technology such as DVDs and video editing software, a necessity to study such a large number of films frame by frame and capture and record their fleeting moments (10). Likewise, she is alert to the additional 
layer of contingency digital copies add to these films' photographic uncertainty. Nevertheless, Frank obstinately passes over the possible repercussions of her findings for present day digital animation. The reader is left to ponder the future of animation without Frank's guidance.

Frame by Frame will undoubtedly and deservedly be influential, indicating the vital stimulus animation studies now plays within film, television and screen studies. The methodological and critical approaches she originates and demonstrates add to the tools at our disposal. Yet the real value and joy of this book is in the inspiration it provides: to look again, to look even more closely, to look differently.

\section{COMPETING INTERESTS}

The author has no competing interests to declare.

\section{AUTHOR AFFILIATION}

Malcolm Cook (D) orcid.org/0000-0001-6604-4207

University of Southampton, GB

TO CITE THIS ARTICLE:

Cook, M. 2021. Book Review: Hannah Frank, Frame by Frame: A Materialist Aesthetics of Animated Cartoons (University of California Press, 2019). Open Screens, 4(1): 12, pp. 1-4. DOI: https://doi.org/10.16995/os.64

Submitted: 30 April 2021 Accepted: 30 April 2021 Published: 07 June 2021

COPYRIGHT:

(C) 2021 The Author(s). This is an open-access article distributed under the terms of the Creative Commons Attribution 4.0 International License (CC-BY 4.0), which permits unrestricted use, distribution, and reproduction in any medium, provided the original author and source are credited. See http://creativecommons.org/licenses/by/4.0/.

Open Screens is a peer-reviewed open access journal published by Open Library of Humanities. 